\title{
The Role of Physical Aerobic Activity in Controlling Exercise-Induced Bronchoconstriction in Children and Adolescents with Asthma
}

\author{
Walid Kamal Abdelbasset ${ }^{1,2^{*}}, \mathrm{PhD}$; Abbas Elbakry A. Elsayed ${ }^{3,4}, \mathrm{MD}$ \\ ${ }^{1}$ Department of Health and Rehabilitation Sciences, College of Applied Medical Sciences, \\ Prince Sattam bin Abdulaziz University, Al-Kharj, Saudi Arabia \\ ${ }^{2}$ Department of Physical Therapy, Kasr Al-Aini Hospital, Cairo University, Giza, Egypt \\ ${ }^{3}$ Department of Pediatrics, College of Medicine, Prince Sattam bin Abdulaziz University, \\ Al-Kharj, Saudi Arabia \\ ${ }^{4}$ Department of Pediatrics, Faculty of Medicine, Al-Azhar University, Assuit, Egypt
}

\begin{abstract}
Asthma, one of the major widespread chronic disorders among children and adolescents, has become more prevalent recently. The common manifestations of this disorder are caused by inflammatory airways that lead to airway restriction and lung hypersensitivity causing dry coughing, wheezing, and shortness of breath, all of which are combined with sleep disturbance, impaired physical activity, and reduced quality of life. The main goal of this brief review was to identify the associated variables that affect the management of asthma disease in children and young adolescents and to identify the role of physical aerobic exercise in the treatment of asthmatic children. The current review was based on prior research published in English databases such as Google Scholar, PubMed, and Embase in scientific articles published between January 2010 and October 2021 with the keywords "asthma," "children," "adolescents," "breathing episodes," "physical activity," and "physical exercise." Regular physical aerobic exercise training with moderate intensity has been shown to improve pulmonary functions, life quality, psychological conditions, and reduce asthma symptoms and EIB in children and adolescents with bronchial asthma.(International Journal of Biomedicine. 2021;11(4):484-487.)
\end{abstract}

Key Words: asthma $\bullet$ children $\bullet$ adolescents $\bullet$ physical activity $\bullet$ exercise-induced bronchoconstriction

For citation: Abdelbasset WK, ElsayedAEA. The Role of Physical Aerobic Activity in Controlling Exercise-Induced Bronchoconstriction in Children and Adolescents with Asthma. International Journal of Biomedicine. 2021;11(4):484-487. doi:10.21103/Article11(4)_BR2

\section{Abbreviations}

EIB, exercise-induced bronchoconstriction; CPET, cardiopulmonary exercise testing.

A sthma is a chronic airway inflammatory disorder that causes repeated sensitive and persistent bouts of pulmonary issues involving shortened breath, wheezing, and cough. ${ }^{(1)}$ These issues may occur as mild, moderate, or severe breathing episodes that require admission to intensive or critical care units and cause a high rate of mortality and

*Corresponding author: Walid Kamal Abdelbasset, PhD. Department of Health and Rehabilitation Sciences, College of Applied Medical Sciences, Prince Sattam bin Abdulaziz University, Al-Kharj, Saudi Arabia.E-mail: walidkamal.wr@gmail.com morbidity. Numerous young asthmatics suffer disturbed quality of life, poor pulmonary functions, and impaired exercise tolerance. ${ }^{(2)}$

It has been documented that regular physical activities is one of the main elements that improve self-esteem, life quality, and psychological status in asthmatic children. ${ }^{3-}$ 5) It has also been reported that, compared with their peers, asthmatic children's levels of physical activities are restricted. Asthmatics had a lower physical activity level than healthy peers in a study of physical activity in urban school-aged children with asthma in America; ${ }^{(6)}$ however, other studies 
reported that asthma disorder does not affect the children's participation in general exercise. ${ }^{(7,8)}$

A recent systematic review of all available studies using a control group identified 11 studies (asthma sample $=32,606$ ) reporting less physical activity in children with asthma, and 6 studies (asthma sample $=7824$ ) reporting no difference, thus leading to the conclusion that people with asthma engage in less activity than do controls. ${ }^{(9)}$

The main goal of this brief review was to identify the associated variables that affect the management of asthma disease in children and young adolescents and to identify the role of physical aerobic exercise in the treatment of asthmatic children. The current review was based on prior research published in English databases such as Google Scholar, PubMed, and Embase in scientific articles published between January 2010 and October 2021 with the keywords "asthma," "children," "adolescents," "breathing episodes," "physical activity," and "physical exercise."

\section{Exercise-induced bronchoconstriction}

Asthma, one of the major widespread chronic disorders among children and adolescents, has become more prevalent recently. ${ }^{(10)}$ The common manifestations of this disorder are caused by inflammatory airways that lead to airway restriction and lung hypersensitivity causing dry coughing, wheezing, and shortness of breath, all of which are combined with sleep disturbance, impaired physical activity, and reduced quality of life. ${ }^{(11)}$ Although regular physical activity is a vital component of well-being during childhood and adolescence, ${ }^{(2)}$ exerciseinduced bronchoconstriction (EIB) can develop when airways narrow as a result of physical activity. ${ }^{(12)}$ EIB is the preferred term for what was known for years as exercise-induced asthma. As many as $90 \%$ of people with asthma also have EIB, but not everyone with EIB has asthma. This condition may occur also in $5 \%$ to $20 \%$ of healthy individuals. ${ }^{(13)} \mathrm{EIB}$ is globally prevalent in $9 \%$ of adolescents and children, $12 \%$ in Asia and America, and 8\% in European countries. ${ }^{(14)}$

EIB symptoms (shortness of breath or wheezing, decreased endurance, tightness in the chest, cough) typically appear within a few minutes after starting exercises and may continue for 10 to 15 minutes after ending the workout. ${ }^{(15)}$ Wheezing in children after physical activity is often the first symptom of asthma. EIB is defined as a forced expiratory volume in one second $\geq 10 \%$ lower than the baseline value at 5, 10, 20, and 30 minutes after cardiopulmonary exercise testing (CPET). ${ }^{(16,17)}$ No clear mechanism has been documented for exercise-induced asthma; however, some associated variables, including dried and cooled airways during exercise, indicate the status of EIB. ${ }^{(18)}$ While physical exercise is the generating factor of bronchospasm, regular exercise training is documented as a primary element in asthma management. Previous meta-analysis and systematic reviews have shown that practicing physical exercise has improved life quality, increased cardiorespiratory performance, and reduced dyspnea in young asthmatics. ${ }^{(19-22)}$

Because bronchial asthma is a common occurrence in adolescents and children, and EIB is identified as a great barrier to participating in physical and sports activities, ${ }^{(23)}$ explaining the effects of physical activity on EIB may help in the development of assessment and management guidelines for therapeutic exercise intervention in adolescents and children experiencing bronchial asthma.

\section{Aerobic exercise training and asthma}

Haskell et al. ${ }^{(24)}$ found that moderate-intensity physical exercise at least $30 \mathrm{~min} 5$ times a week or high-intensity physical exercise at least $20 \mathrm{~min} 3$ times a week are required to control and prevent diseases. It was documented that the most beneficial modality of physical activity is moderate-intensity physical exercise for a longer time than high-intensity physical exercise. ${ }^{(25,26)}$

Aerobic exercise, sometimes known as "cardio" exercise, stimulates the heart to pump oxygenated blood to deliver oxygen to working muscles. The oxygen inhaled and demanded is needed to maintain vital physiological mechanisms in the human body during activities. It was documented that moderate-intensity aerobic training improves pulmonary inflammatory markers in an asthmatic mouse model. ${ }^{(27)} \mathrm{A}$ six-minute walk test in school-aged asthmatics found that moderate-intensity physical exercise improves life quality, lung functions, and exercise tolerance. ${ }^{(2)}$

Different studies have demonstrated that various intensities of aerobic and active play exercises may improve life quality, lung volumes, functional capacity, sleep disturbances, cardiac output, immunity, and psychological condition in different respiratory and cardiovascular diseases at different age stages. ${ }^{(28-32)}$

Children and adolescents with asthma should be encouraged to engage in regular physical activity. ${ }^{(33)}$ Recent reviews have endorsed the positive influences of physical exercise on asthma symptoms, maximal oxygen uptake, cardiorespiratory fitness, and life quality in adults experiencing bronchial asthma, without adverse impacts on pulmonary functions. ${ }^{(21,34-36)}$ Regular aerobic exercise improved asthma symptom management, lung function, physical capacity, body composition, and mental health in children with asthma. ${ }^{(37,38)}$

In addition, it was observed that aerobic exercise alone or combined with resistance exercise can improve the exercise tolerance of abdominal muscles in obese adolescents. ${ }^{(39)}$ Similarly, it was reported that airway obstructions have been reduced and inspiratory muscle strength has been increased in asthmatic adults following an aerobic exercise program. ${ }^{(40)}$

In a population-based study conducted in Greece by Anthracopoulos et al., ${ }^{(41)}$ free-running exercise challenge tests were employed in the evaluation of children 10-12 years of age. The authors found that the prevalence of EIB and the total energy expenditure were higher in the children who were moderately active or inactive than in those who were active, regardless of body mass index or asthma symptoms.

Lu et al. found that increased sedentary time is associated with worse asthma outcomes. ${ }^{(42)}$ In a study performed by Sousa et al., ${ }^{(43)}$ the level of moderate physical activity was found to be comparable between children with and without asthma, even when those with severe asthma were included, although EIB was not evaluated in that study.

Vahlkvist et al. ${ }^{(44)}$ showed that poorly controlled asthma was associated with reduced physical activity and cardiovascular fitness. Faleiro et al. ${ }^{(33)}$ evaluated 20 patients with severe 
refractory asthma and 19 controls. In the sample as a whole, the mean age was $12.9 \pm 0.4$ years. Among the patients, authors observed isolated EIB in 30\%, isolated physical deconditioning in $25 \%$, physical deconditioning accompanied by EIB in $25 \%$, and exercise-induced symptoms not supported by the CPET data in $15 \%$. The authors concluded that physical deconditioning (alone or accompanied by EIB) was the determining factor in reducing exercise tolerance in patients with severe refractory asthma and was not therefore found to be associated with a lack of asthma control.

A meta-analysis of 17 randomized controlled trials, including 599 children and adult asthmatics, also reported that exercise training led to a significant improvement in days without asthma symptoms. ${ }^{(45)}$ A clinical review performed by Panagiotou et al. ${ }^{(16)}$ showed that higher adherence to physical activity was associated with favorable clinical outcomes, such as improved lung function, asthma control, exacerbation rate, and healthcare use.

\section{Conclusion}

In general, regular physical aerobic exercise training with moderate intensity may improve pulmonary functions, life quality, psychological conditions, and reduce asthma symptoms and EIB in children and adolescents with bronchial asthma. Regular physical aerobic exercise training should be conducted in combination with pharmacological asthma treatment to achieve significant asthma control in children and adolescents.

\section{Acknowledgments}

This publication was supported by the Deanship of Scientific Research at Prince Sattam bin Abdulaziz University.

\section{Competing Interests}

The authors declare that they have no competing interests.

\section{References}

1. Wu WF, Wan KS, Wang SJ, Yang W, Liu WL. Prevalence, severity, and time trends of allergic conditions in 6-to-7-yearold schoolchildren in Taipei. J Investig Allergol Clin Immunol. 2011;21(7):556-62.

2. Abdelbasset WK, Alsubaie SF, Tantawy SA, Abo Elyazed TI, Kamel DM. Evaluating pulmonary function, aerobic capacity, and pediatric quality of life following a 10week aerobic exercise training in school-aged asthmatics: a randomized controlled trial. Patient Prefer Adherence. 2018 Jun 15;12:1015-1023. doi: 10.2147/PPA.S159622.

3. Robinson PD, Van Asperen P. Update in paediatric asthma management: where is evidence challenging current practice? J Paediatr Child Health. 2013 May;49(5):346-52. doi: 10.1111/j.1440-1754.2010.01975.x.

4. Karkera A, Swaminathan N, Pais SM, Vishal K, Rai B S. Physical fitness and activity levels among urban school children and their rural counterparts. Indian J Pediatr. 2014
Apr;81(4):356-61. doi: 10.1007/s12098-013-1033-8.

5. Ullrich-French S, McDonough MH. Correlates of longterm participation in a physical activity-based positive youth development program for low-income youth: sustained involvement and psychosocial outcomes. J Adolesc. 2013 Apr;36(2):279-88. doi: 10.1016/j.adolescence.2012.11.006.

6. Lang DM, Butz AM, Duggan AK, Serwint JR. Physical activity in urban school-aged children with asthma. Pediatrics. 2004 Apr;113(4):e341-6. doi: 10.1542/peds.113.4.e341.

7. van Gent $R$, van der Ent CK, van Essen-Zandvliet LE, Rovers MM, Kimpen JL, de Meer G, Klijn PH. No differences in physical activity in (un)diagnosed asthma and healthy controls. Pediatr Pulmonol. 2007 Nov;42(11):1018-23. doi: 10.1002/ppul.20672.

8. Nystad W. The physical activity level in children with asthma based on a survey among 7-16 year old school children. Scand J Med Sci Sports. 1997 Dec;7(6):331-5. doi: 10.1111/j.1600-0838.1997.tb00162.x.

9. Cordova-Rivera L, Gibson PG, Gardiner PA, McDonald VM. A Systematic Review of Associations of Physical Activity and Sedentary Time with Asthma Outcomes. J Allergy Clin Immunol Pract. 2018 Nov-Dec;6(6):1968-1981. e2. doi: 10.1016/j.jaip.2018.02.027.

10. Ribeiro-Silva RC, Barreto ML, Ramos D, Cruz AA, Oliveira-Campos M, Malta DC. Asthma trend in adolescence in Brazil: results of the National Adolescent School-based Health Survey (PeNSE 2012-2015). Rev Bras Epidemiol. 2018 Nov 29;21(suppl 1):e180017. doi: 10.1590/1980549720180017.supl.1.

11. Sociedade Brasileira de Pneumologia e Tisiologia. Diretrizes Brasileiras para o Manejo da Asma - 2012. J Bras Pneumol. 2012;38(suppl 1):S1-46.

12. Assis FM, Correia Jonior MA, Peixoto DM, Sarinho ES, Sarinho SW, Silva AR, et al. Broncoespasmo induzido por exercicio, atividade fisica e suas limitaçoes em crianças e adolescentes. Rev Bras Alerg Imunopatol. 2011;34(2):33-41.

13. Bonini M, Silvers W. Exercise-Induced Bronchoconstriction: Background, Prevalence, and Sport Considerations. Immunol Allergy Clin North Am. 2018 May;38(2):205-214. doi: 10.1016/j.iac.2018.01.007.

14. de Aguiar KB, Anzolin M, Zhang L. Global prevalence of exercise-induced bronchoconstriction in childhood: A metaanalysis. Pediatr Pulmonol. 2018 Apr;53(4):412-425. doi: 10.1002/ppul.23951.

15. Weiler JM, Brannan JD, Randolph CC, Hallstrand TS, Parsons J, Silvers W, Storms W, Zeiger J, Bernstein DI, Blessing-Moore J, Greenhawt M, Khan D, Lang D, Nicklas RA, Oppenheimer J, Portnoy JM, Schuller DE, Tilles SA, Wallace D. Exercise-induced bronchoconstriction update-2016. J Allergy Clin Immunol. 2016 Nov; 138(5):1292-1295.e36. doi: 10.1016/j.jaci.2016.05.029.

16. Panagiotou M, Koulouris NG, Rovina N. Physical Activity: A Missing Link in Asthma Care. J Clin Med. 2020 Mar 5;9(3):706. doi: 10.3390/jcm9030706.

17. Price OJ, Hull JH, Ansley L. Advances in the diagnosis of exercise-induced bronchoconstriction. Expert Rev Respir Med. 2014 Apr;8(2):209-20. doi: 10.1586/17476348.2014.890517. 18. van Leeuwen JC, Driessen JM, Kersten ET, Thio BJ. Assessment of exercise-induced bronchoconstriction in adolescents and young children. Immunol Allergy Clin North Am. 2013 Aug;33(3):381-94, viii-ix. doi: 10.1016/j. iac.2013.02.007.

19. Wanrooij VH, Willeboordse M, Dompeling E, van 
de Kant KD. Exercise training in children with asthma: a systematic review. Br J Sports Med. 2014 Jul;48(13):1024-31. doi: 10.1136/bjsports-2012-091347.

20. Eichenberger PA, Diener SN, Kofmehl R, Spengler CM. Effects of exercise training on airway hyperreactivity in asthma: a systematic review and meta-analysis. Sports Med. 2013 Nov;43(11):1157-70. doi: 10.1007/s40279-013-0077-2.

21. Carson KV, Chandratilleke MG, Picot J, Brinn MP, Esterman AJ, Smith BJ. Physical training for asthma. Cochrane Database Syst Rev. 2013 Sep 30;(9):CD001116. doi: 10.1002/14651858.CD001116.pub4.

22. Welsh L, Kemp JG, Roberts RG. Effects of physical conditioning on children and adolescents with asthma. Sports Med. 2005;35(2):127-41. doi: 10.2165/00007256200535020-00003.

23. Côté A, Turmel J, Boulet LP. Exercise and Asthma. Semin Respir Crit Care Med. 2018 Feb;39(1):19-28. doi: 10.1055/s0037-1606215.

24. Haskell WL, Lee IM, Pate RR, Powell KE, Blair SN, Franklin BA, Macera CA, Heath GW, Thompson PD, Bauman A. Physical activity and public health: updated recommendation for adults from the American College of Sports Medicine and the American Heart Association. Med Sci Sports Exerc. 2007 Aug;39(8):1423-34. doi: 10.1249/ mss.0b013e3180616b27.

25. Karjalainen EM, Laitinen A, Sue-Chu M, Altraja A, Bjermer L, Laitinen LA. Evidence of airway inflammation and remodeling in ski athletes with and without bronchial hyperresponsiveness to methacholine. Am J Respir Crit Care Med. 2000 Jun;161(6):2086-91. doi: 10.1164/ ajrccm.161.6.9907025.

26. Westerterp KR. Pattern and intensity of physical activity. Nature. 2001 Mar 29;410(6828):539. doi: 10.1038/35069142. 27. Pastva A, Estell K, Schoeb TR, Atkinson TP, Schwiebert LM. Aerobic exercise attenuates airway inflammatory responses in a mouse model of atopic asthma. J Immunol. 2004 Apr 1;172(7):4520-6. doi: 10.4049/jimmunol.172.7.4520.

28. Abdelbasset WK, Alrawaili SM, Nambi G, Yassen E, Moawd SA, Ahmed AS. Therapeutic effects of proprioceptive exercise on functional capacity, anxiety, and depression in patients with diabetic neuropathy: a 2-month prospective study. Clin Rheumatol. 2020 Oct;39(10):3091-3097. doi: 10.1007/s10067-020-05086-4.

29. Abdelbasset WK, Elsayed SH, Nambi G, Alrawaili SM, Elnegamy TE, Khalil MA, et al. Effect of Moderate-Intensity Aerobic Exercise on Hepatic Fat Content and Visceral Lipids in Hepatic Patients with Diabesity: A Single-Blinded Randomised Controlled Trial. Evid Based Complement Alternat Med. 2020 Apr 11;2020:1923575. doi: 10.1155/2020/1923575.

30. Abdelbasset WK, Osailan A. Sleep quality and ventilatory efficiency in elderly heart failure patients: a pilot study on the short-term effect of 4-week low-intensity aerobic exercise. Kardiologiia. 2020 Jul 7;60(6):938. doi: 10.18087/ cardio.2020.6.n938.

31. Elsayed S, Kamal W, Fathy K. Impact of active cycle of breathing technique on functional capacity in patient with bronchiectasis. Int $J$ Ther Rehabil Res. 2015;4(5):287-293. 32. Abdelbasset WK. Stay Home: Role of Physical Exercise Training in Elderly Individuals' Ability to Face the COVID-19
Infection. J Immunol Res. 2020 Nov 28;2020:8375096. doi: $10.1155 / 2020 / 8375096$.

33. Faleiro RC, Mancuzo EV, Lanza FC, Queiroz MVNP, de Oliveira LFL, Ganem VO, Lasmar LB. Exercise Limitation in Children and Adolescents With Severe Refractory Asthma: A Lack of Asthma Control? Front Physiol. 2021 Jan 26;11:620736. doi: 10.3389/fphys.2020.620736.

34. Francisco CO, Bhatawadekar SA. Effects of physical exercise training on nocturnal symptoms in asthma: Systematic review. PLoS One. 2018;13:e0204953.

35. Pacheco DR, Silva MJ, Alexandrino AM, Torres RM. Exercise-related quality of life in subjects with asthma: a systematic review. J Asthma. 2012 Jun;49(5):487-95. doi: 10.3109/02770903.2012.680636.

36. Ram FS, Robinson SM, Black PN, Picot J. Physical training for asthma. Cochrane Database Syst Rev. 2005 Oct 19;(4):CD001116. doi: 10.1002/14651858.CD001116.pub2. Update in: Cochrane Database Syst Rev. 2012;5:CD001116. 37. Latorre-Román PÁ, Navarro-Martínez AV, GarcíaPinillos F. The effectiveness of an indoor intermittent training program for improving lung function, physical capacity, body composition and quality of life in children with asthma. J Asthma. 2014 Jun;51(5):544-51. doi: 10.3109/02770903.2014.888573.

38. Avallone KM, McLeish AC. Asthma and aerobic exercise: a review of the empirical literature. J Asthma. 2013 Mar;50(2):109-16. doi: 10.3109/02770903.2012.759963.

39. Alberga AS, Prud'homme D, Sigal RJ, Goldfield GS, Hadjiyannakis S, Phillips P, Malcolm J, Ma J, Doucette S, Gougeon R, Wells GA, Kenny GP. Effects of aerobic training, resistance training, or both on cardiorespiratory and musculoskeletal fitness in adolescents with obesity: the HEARTY trial. Appl Physiol Nutr Metab. 2016 Mar;41(3):25565. doi: 10.1139/apnm-2015-0413.

40. Shaw BS, Shaw I. Pulmonary function and abdominal and thoracic kinematic changes following aerobic and inspiratory resistive diaphragmatic breathing training in asthmatics. Lung. 2011 Apr;189(2):131-9. doi: 10.1007/s00408-011-9281-8. 41. Anthracopoulos MB, Fouzas S, Papadopoulos M, Antonogeorgos G, Papadimitriou A, Panagiotakos DB, Nicolaidou P, Priftis KN. Physical activity and exerciseinduced bronchoconstriction in Greek schoolchildren. Pediatr Pulmonol. 2012 Nov;47(11):1080-7. doi: 10.1002/ppul.22620. 42. Lu KD, Forno E, Radom-Aizik S, Cooper DM. Low fitness and increased sedentary time are associated with worse asthma-The National Youth Fitness Survey. Pediatr Pulmonol. 2020 May;55(5):1116-1123. doi: 10.1002/ppul.24678.

43. Sousa AW, Cabral AL, Martins MA, Carvalho CR. Daily physical activity in asthmatic children with distinct severities. J Asthma. 2014 Jun;51(5):493-7. doi: 10.3109/02770903.2014.888571.

44. Vahlkvist S, Inman MD, Pedersen S. Effect of asthma treatment on fitness, daily activity and body composition in children with asthma. Allergy. 2010 Nov;65(11):1464-71. doi: 10.1111/j.1398-9995.2010.02406.x.

45. Eichenberger P.A., Diener S.N., Kofmehl R., Spengler C.M. Effects of exercise training on airway hyperreactivity in asthma: A systematic review and meta-analysis. Sports Med. 2013;43:1157-1170. doi: 10.1007/s40279-013-0077-2. 